\title{
Effects of olfactory stimulation by $\alpha$-pinene on autonomic nervous activity
}

\author{
Harumi Ikei $^{1,2} \cdot$ Chorong Song $^{1} \cdot$ Yoshifumi Miyazaki $^{1}$ (I)
}

Received: 17 March 2016/Accepted: 21 July 2016/Published online: 4 August 2016

(c) The Author(s) 2016. This article is published with open access at Springerlink.com

Keywords $\alpha$-Pinene $\cdot$ Smell $\cdot$ Physiological relaxation . Heart rate variability $\cdot$ Semantic differential method

\section{Introduction}

Wood has been used as building material and for making furniture since a long time, and it has been known from experience that woody smell acts as a mood relaxant. Several studies on the physiological and psychological effects of wood or wood-derived smells have been conducted [1-7]. The inhalation of air containing volatile organic compounds released from the interior walls of Japanese cedar suppresses increases in salivary chromogranin A [1]. Olfactory stimulation by Japanese cedar chips decreases systolic blood pressure and prefrontal cortex activity [2]. Olfactory stimulation by air-dried wood chips of Japanese cypress, which is commonly found and is widely used as a building material in Japan, reduced the oxygenated hemoglobin concentration in the prefrontal cortex [3]. Moreover, it has been reported that staying at

Part of this study was presented at the 71st Meeting of Japan Society of Physiological Anthropology, Hyogo, November 2014.

H. Ikei and C. Song co-first authors that contributed equally to this work.

Yoshifumi Miyazaki

ymiyazaki@faculty.chiba-u.jp

1 Center for Environment, Health and Field Sciences, Chiba University, 6-2-1 Kashiwa-no-ha, Kashiwa, Chiba 277-0882, Japan

2 Present Address: Forestry and Forest Products Research Institute, 1 Matsunosato, Tsukuba, Ibaraki 305-8687, Japan night in a hotel room filled with the smell of Japanese cypress essential oil for three consecutive nights induces natural killer cell activity and reduces the concentrations of adrenaline and noradrenaline in urine [4]. Olfactory stimulation by the essential oil from Japanese cypress leaf enhances parasympathetic nervous activity and decreases prefrontal cortex activity; in a subjective evaluation, the stimulation was assessed to be "comfortable" [5]. Inhalation of D-limonene, which is a major component of conifer wood extracts such as Japanese cedar and Japanese cypress, enhanced parasympathetic nervous activity and decreased heart rate; in a subjective evaluation, the stimulation was also assessed to be "comfortable" [6]. Inhalation of cedrol, a compound found in cedar extract, induced parasympathetic nervous activity and reduced sympathetic nervous activity [7].

$\alpha$-Pinene is a typical volatile compound present in Japanese cedar wood [8], which is used as a general architectural material. It is also the main component responsible for the smell in forests [9]. Studies using rats or mice have reported the physiological effects of $\alpha$-pinene in rodent species $[10,11]$. In human studies, Tsunetsugu et al. [12] investigated the effects of $\alpha$-pinene on 15 male college students. They found that olfactory stimulation with $\alpha$ pinene, which was rated as a "slight smell", decreased systolic blood pressure and was assessed as "slightly comfortable" in the subjective evaluation [12]. However, no study has evaluated the physiological effects of $\alpha$ pinene inhalation on adult females using heart rate variability (HRV) as an index.

In this study, we investigated the effects of olfactory stimulation by $\alpha$-pinene on autonomic nervous activity based on the assessment of parasympathetic nervous activity and sympathetic nervous activity using HRV and heart rate in young adult females. 


\section{Materials and methods}

Thirteen Japanese young adult females were recruited. In addition, none of the participants were menstruating on the day of the experiment. The participants who participated in the study had a mean age ( \pm standard deviation) of $21.5 \pm 1.0$ years. All participants were informed about the aims and procedures involved in the experiment provided their written informed consent for participation. This study was performed in accordance with the regulations of the Ethics Committee of the Center for Environment, Health and Field Sciences, Chiba University, Japan.

Physiological measurements of the participants were performed in a chamber with an artificial climate maintained at $25{ }^{\circ} \mathrm{C}, 50 \%$ relative humidity, and $230 \mathrm{~lx}$ illumination. After fitting the sensors for the physiological measurements, participants received a description of the measurement procedure again for $10 \mathrm{~min}$ while sitting. The participants then rested by sitting with their eyes closed, and the smell was administered for $90 \mathrm{~s}$; subsequently, the subjective evaluation test was performed. A crossover trial to eliminate any effects due to the order of olfactory stimulation was performed. Approximately half the participants were administered stimuli in the following order: exposure to $\alpha$-pinene followed by control (air). The remaining participants were presented with the control followed by $\alpha$-pinene.

$\alpha$-Pinene (Tokyo Chemical Industry Co., Ltd., Japan) was used as the olfactory stimulant, and air was used as the control. To administer the stimulation, $\alpha$-pinene $(20 \mu \mathrm{L})$ was injected into a smell bag (polyethylene terephthalate film heat seal bag; NS-KOKEN Co., Ltd., Japan) filled with $24 \mathrm{~L}$ air. After vaporizing the $\alpha$-pinene in the smell bag using a dryer, the smell bag was incubated for approximately $1 \mathrm{~h}$ at room temperature to diffuse the $\alpha$-pinene into the bag. Smells were administered to each participant by means of a device fixed on the chest and situated approximately $10 \mathrm{~cm}$ under the nose (Fig. 1). The flow rate of the air saturated with $\alpha$-pinene was $3 \mathrm{~L} / \mathrm{min}$. Preliminary investigations determined that the subjective intensity of the smell was "weak" or "easily sensed".

As an indicator of physiological condition, HRV was analyzed using the periods between consecutive $\mathrm{R}$ waves ( $\mathrm{R}-\mathrm{R}$ intervals) on electrocardiograms measured using a portable electrocardiograph (Activtracer AC-301A; GMS, Japan) [13, 14]. This device performs measurements using a 3-lead electrocardiogram (Lead II). The power levels of the low-frequency (LF: 0.04-0.15 Hz) and high-frequency (HF: 0.15-0.40 Hz) components of HRV were calculated using the maximum entropy method (MemCalc/Win; GMS, Japan) [15]. The HF power reflects parasympathetic nervous activity, which increases in the relaxed state. The $\mathrm{LF} /(\mathrm{LF}+\mathrm{HF})$ ratio reflects sympathetic nervous activity, which increases in the arousal or stressed state. Data were

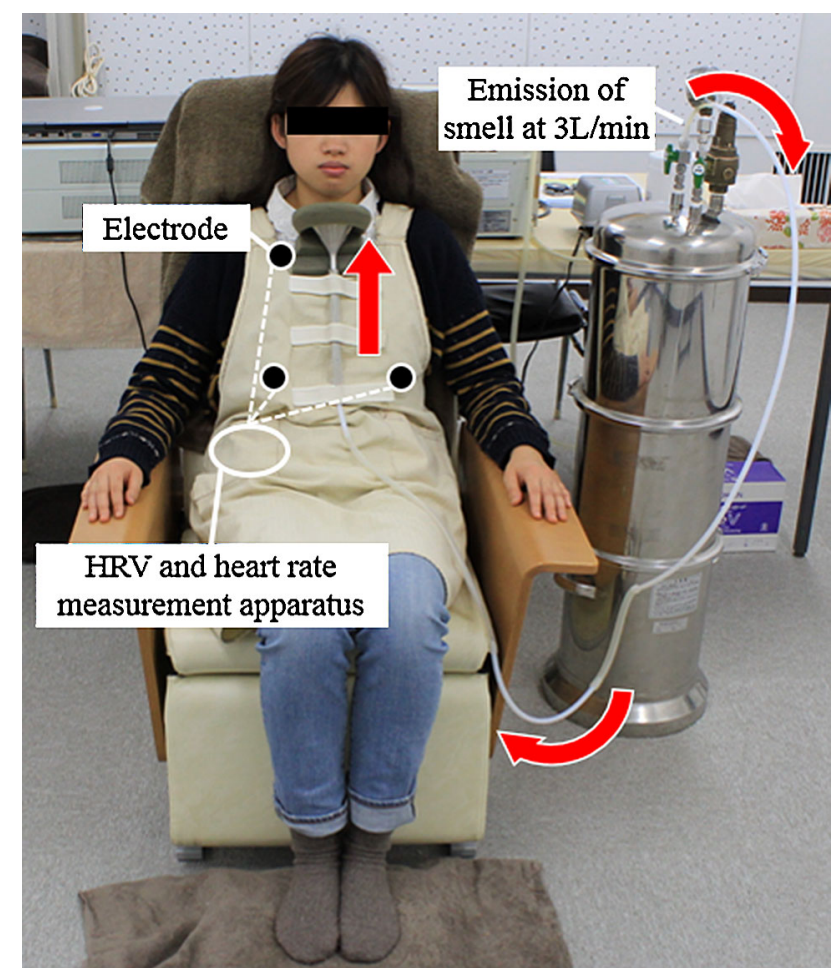

Fig. 1 Olfactory stimulation setup

acquired for $30 \mathrm{~s}$ before smell administration and during the 90-s smell administration. Heart rate was also investigated using $\mathrm{R}-\mathrm{R}$ interval data.

To subjectively evaluate the psychological effect of the smell, the participants were tested using the modified semantic differential (SD) method [16]. Three pairs of adjectives were assessed on 13 scales as "comfortable-uncomfortable", "relaxed-awakening", and "natural-artificial".

All data are shown as the mean \pm standard error. Physiological and psychological tests were used to compare $\alpha$-pinene with the control. All statistical analyses were performed using Statistical Package for Social Sciences version 20.0 software (IBM Corp., Armonk, NY, USA). A paired $t$ test was used to compare the physiological responses to $\alpha$-pinene with those to the control. The Wilcoxon signed-rank test was used to analyze differences in psychological indices between the responses to the $\alpha$-pinene and those to the control. A one-sided test was used in this study because of the hypothesis that humans would be relaxed on inhaling $\alpha$-pinene. In all cases, the significance level was set at $P<0.05$.

\section{Results and discussion}

The HF value associated with olfactory stimulation by $\alpha$ pinene is shown in Fig. 2a. The mean baseline HF for $30 \mathrm{~s}$ before stimulation (pre-measurement condition) did not 
differ significantly between the $\alpha$-pinene group $\left(760.0 \pm 249.7 \mathrm{~ms}^{2}\right)$ and control group (793.2 \pm $287.2 \mathrm{~ms}^{2}$ ). Figure $2 \mathrm{~b}$ shows the overall mean of the HF value associated with olfactory stimulation by $\alpha$-pinene. When the results of the HRV power level data were compared, a significant difference was found in the HF power level between the $\alpha$-pinene and control groups $(P<0.05)$. The HF power level of $\alpha$-pinene $\left(967.3 \pm 192.3 \mathrm{~ms}^{2}\right)$ was $46.8 \%$ higher than that of the control group $\left(658.7 \pm 161.8 \mathrm{~ms}^{2}\right)$. It was clear that olfactory stimulation by the $\alpha$-pinene induced a significant increase in parasympathetic nervous activity and thereby induced physiological relaxation. However, no significant difference was found in the $\mathrm{LF} /(\mathrm{LF}+\mathrm{HF})$ ratio between groups receiving the two stimuli ( $\alpha$-pinene, $0.30 \pm 0.05$; control, $0.35 \pm 0.06)$.

Figure 3 shows the heart rates measured during olfactory stimulation by $\alpha$-pinene or control. The mean baseline heart rate at $30 \mathrm{~s}$ before stimulation (premeasurement condition) did not differ significantly between the $\alpha$-pinene group $(73.3 \pm 2.4 \mathrm{beats} / \mathrm{min})$ and the control group ( $74.5 \pm 2.6$ beats/min), which is similar to the results observed with regard to the HF component. The mean heart rate during olfactory stimulation by $\alpha$-pinene remained lower than that of the control and gradually decreased from the baseline (Fig. 3a). A comparison of the mean heart rates of 90 -s olfactory stimulation by $\alpha$-pinene and control is shown in Fig. 3b. Olfactory stimulation by $\alpha$-pinene significantly decreased the heart rate compared with control (Fig. 3b, $P<0.05$ ). The heart rate of $\alpha$-pinene group $(72.0 \pm 2.3$ beats/min) was $2.8 \%$ lower than that of the control group $(74.1 \pm 2.6$ beats/min).

The modified SD method was used to provide subjective reports of "comfortable", "relaxed", and "natural" feelings (Fig. 4). When subjected to the stimulation by $\alpha$ pinene, participants provided subjective reports of feeling "slightly comfortable"; however, they provided reports of feeling "indifferent" when subjected to the control. Therefore, the response to $\alpha$-pinene was perceived as being significantly more comfortable than that to the control (Fig. 4 left, $P<0.05$ ). Although the differences were not statistically significant, the results suggest that $\alpha$-pinene was more "relaxed" and "natural" than the control (Fig. 4 center, $P=0.077$ and right, $P=0.097$ ).

This study was designed to clarify the effects of olfactory stimulation by $\alpha$-pinene on autonomic nervous activity. The effects were assessed by measuring HRV and heart rates of young adult females. The results showed that olfactory stimulation with $\alpha$-pinene significantly increased parasympathetic nervous activity and significantly decreased heart rate.

Our previous studies of HRV demonstrated significant differences in parasympathetic nervous activity but not in sympathetic nervous activity. Olfactory stimulation by Japanese cypress leaf oil and inhalation of D-limonene enhanced parasympathetic nervous activity by 34.5 and $26.4 \%$, respectively, compared with a control (air) $[5,6]$; these findings were in accordance with the results of our previous laboratory experiments $[17,18]$. In our forest therapy field experiment, which included a large sample size of 625 participants [19], 79.2\% of the participants showed an increase in parasympathetic nervous activity in a forest environment compared with that in an urban environment. However, only $63.5 \%$ of the participants exhibited decreases in sympathetic nervous activity [19]. Based on these findings, we concluded that the parasympathetic nervous activity index of HRV was more sensitive than the sympathetic nervous activity index.

Subjective evaluations demonstrate that the participants felt more comfortable after olfactory stimulation by $\alpha$ pinene than by the control. Olfactory stimulation by $\alpha$ pinene, which were rated as "slight smell", was assessed to
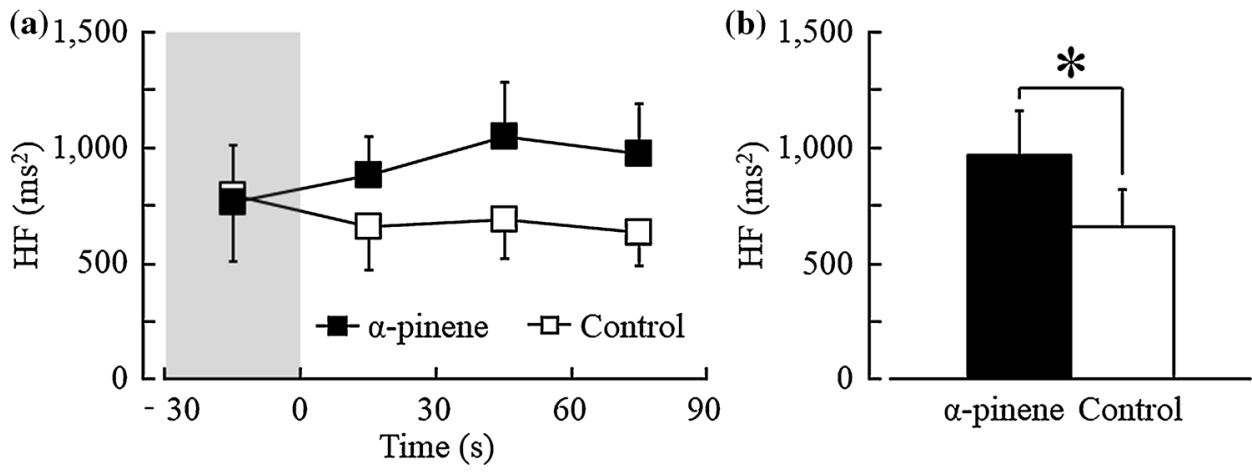

Fig. 2 The 30-s means and overall mean high-frequency (HF) component of heart rate variability (HRV) during olfactory stimulation by $\alpha$-pinene or control. a Changes in each 30 -s mean HF value over $90 \mathrm{~s}$. b Overall mean HF values. Data are expressed as the mean \pm standard error; $N=13 ; * P<0.05$ as determined using the paired $t$ test (one sided) 
Fig. 3 The 30-s means and overall mean heart rate during olfactory stimulation by $\alpha-$ pinene or control. a Changes in each 30-s mean heart rate over $90 \mathrm{~s}$. b Overall mean heart rate. Data are expressed as the mean \pm standard error, $N=13$, $* P<0.05$ as determined using the paired $t$ test (one sided)
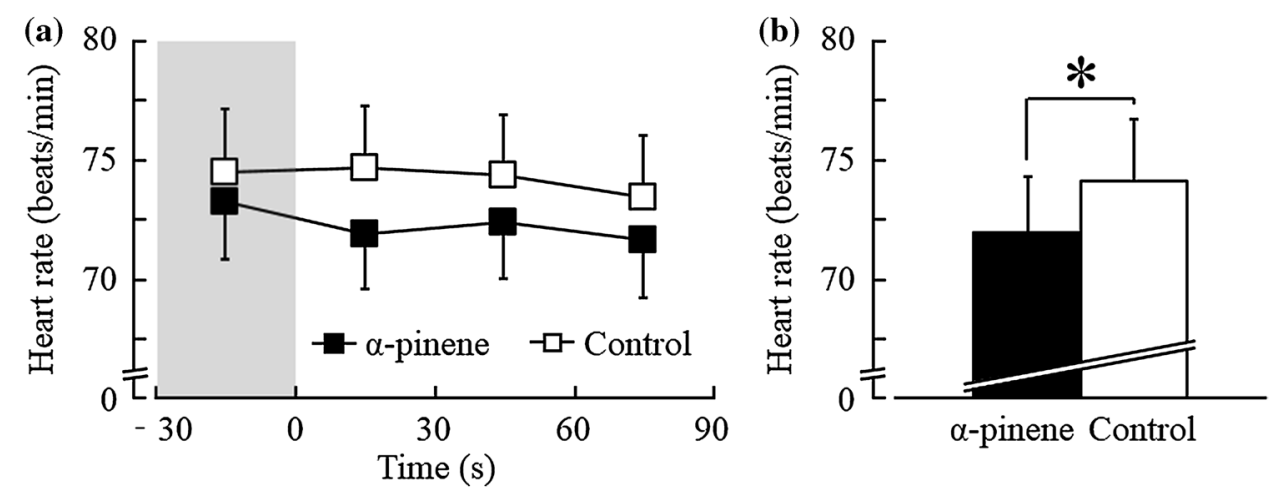

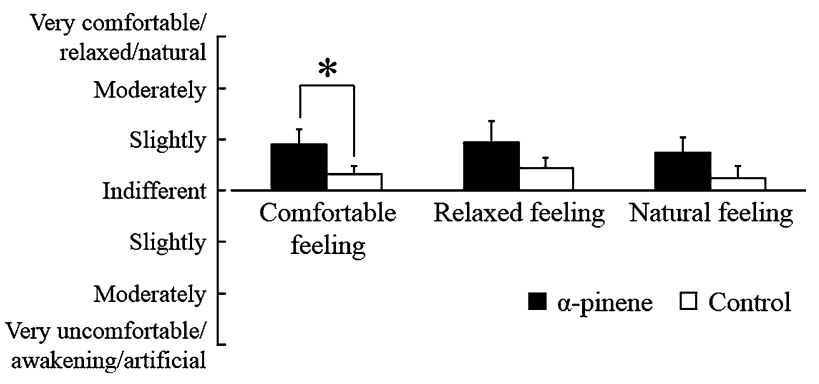

Fig. 4 Subjective feelings measured by the modified semantic differential method after olfactory stimulation by $\alpha$-pinene or control. Data are expressed as the mean \pm standard error, $N=13, * P<0.05$ as determined by the Wilcoxon signed-rank test (one sided)

be "slightly comfortable" in the subjective evaluation [12]; this finding is consistent with the results of this study. The results of this study also match those of previous studies, including studies of D-limonene from wood-derived components [6] and Japanese cypress leaf oil [5].

Wood is a familiar natural material because it is globally used as a building material or for making furniture. In recent years, the accumulation of data on the physiological effects of wood or wood-derived stimuli, such as smell $[1-7,12]$, viewing [20-22], and touch [23], has been promoted. In this study, we clarified the physiological relaxation effects of olfactory stimulation by $\alpha$-pinene. In the future, it is possible that accumulating scientific evidence about wood-derived smells and clarifying the physiological relaxation effects on individuals living in areas in which substantial quantities of wood are present will help improve the quality of life of modern people.

Although this study evaluated autonomic nervous activity, other experimental indices such as brain activity, which can be measured using near-infrared spectroscopy, and stress hormone levels, which can be measured using salivary cortisol concentration, should be assessed to more comprehensively evaluate the physiological effects of olfactory stimulation by $\alpha$-pinene. In addition, the participants of this study were young adult females. Studies on males, minors, and elderly are required.

\section{Conclusions}

Olfactory stimulation by $\alpha$-pinene significantly increased the HF component of HRV, which is associated with parasympathetic nervous activity, and significantly decreased heart rate. These findings indicate that olfactory stimulation by $\alpha$-pinene induces physiological relaxation.

Acknowledgments This study was conducted as a research project from the Vehicle Racing Commemorative Foundation. In addition, we would like to express our sincere thanks to Ms. Dawou Joung for valuable contribution to data collection.

Open Access This article is distributed under the terms of the Creative Commons Attribution 4.0 International License (http://crea tivecommons.org/licenses/by/4.0/), which permits unrestricted use, distribution, and reproduction in any medium, provided you give appropriate credit to the original author(s) and the source, provide a link to the Creative Commons license, and indicate if changes were made.

\section{References}

1. Matsubara E, Kawai S (2014) VOCs emitted from Japanese cedar (Cryptomeria japonica) interior walls induce physiological relaxation. Build Environ 72:125-130

2. Tsunetsugu Y, Park BJ, Miyazaki Y (2012) Physiological effects of visual, olfactory, auditory, and tactile factors of forest environments. In: Li Q (ed) Forest medicine. Nova Science Publishers, New York, pp 169-181

3. Ikei H, Song C, Lee J, Miyazaki Y (2015) Comparison of the effects of olfactory stimulation by air-dried and high-temperature-dried wood chips of Hinoki cypress (Chamaecyparis obtusa) on prefrontal cortex activity. J Wood Sci 61:537-540

4. Li Q, Kobayashi M, Wakayama Y, Inagaki H, Katsumata M, Hirata Y, Hirata K, Shimizu T, Kawada T, Park BJ, Ohira T, Kagawa T, Miyazaki Y (2009) Effect of phytoncide from trees on human natural killer cell function. Int J Immunopathol Pharmacol 22:951-959

5. Ikei H, Song C, Miyazaki Y (2015) Physiological effect of olfactory stimulation by Hinoki cypress (Chamaecyparis obtusa) leaf oil. J Physiol Anthropol 34:44

6. Joung D, Song C, Ikei H, Okuda T, Igarashi M, Koizumi H, Park BJ, Yamaguchi T, Takagaki M, Miyazaki Y (2014) Physiological and psychological effects of olfactory stimulation with D-limonene. Adv Hortic Sci 28:90-94 
7. Dayawansa S, Umeno K, Takakura H, Hori E, Tabuchi E, Nagashima Y, Oosu H, Yada Y, Suzuki T, Ono T, Nishijo H (2003) Autonomic responses during inhalation of natural fragrance of Cedrol in humans. Auton Neurosci 108:79-86

8. Ohira T, Park BJ, Kurosumi Y, Miyazaki Y (2009) Evaluation of dried-wood odors: comparison between analytical and sensory data on odors from dried sugi (Cryptomeria japonica) wood. J Wood Sci 55:144-148

9. Lee J, Park BJ, Tsunetsugu Y, Ohira T, Kagawa T, Miyazaki Y (2010) Effect of forest bathing on physiological and psychological responses in young Japanese male subjects. Public Health 125:93-100

10. Akutsu H, Kikusui T, Takeuchi Y, Sano K, Hatanaka A, Mori Y (2002) Alleviating effects of plant-derived fragrances on stressinduced hyperthermia in rats. Physiol Behav 75:355-360

11. Kusuhara M, Urakami K, Masuda Y, Zangiacomi V, Ishii H, Tai S, Maruyama K, Yamaguchi K (2012) Fragrant environment with $\alpha$-pinene decreases tumor growth in mice. Biomed Res 33:57-61

12. Tsunetsugu Y, Park BJ, Miyazaki Y (2010) Trends in research related to "Shinrin-yoku" (taking in the forest atmosphere or forest bathing) in Japan. Environ Health Prev Med 15:27-37

13. Task Force of the European Society of Cardiology and the North American Society of Pacing and Electrophysiology (1996) Heart rate variability: standards of measurement, physiological interpretation and clinical use. Circulation 93:1043-1065

14. Kobayashi H, Ishibashi K, Noguchi H (1999) Heart rate variability; an index for monitoring and analyzing human autonomic activities. J Physiol Anthropol Appl Hum Sci 18:53-59

15. Sawada Y, Ohtomo N, Tanaka Y, Tanaka G, Yamakoshi K, Terachi S, Shimamoto K, Nakagawa M, Satoh S, Kuroda S,
Iimura O (1997) New technique for time series analysis combining the maximum entropy method and non-linear least squares method: its value in heart rate variability analysis. Med Biol Eng Comput 35:318-322

16. Osgood CE, Suci GJ, Tannenbaum P (1957) The measurement of meaning. University of Illinois Press, Urbana

17. Igarashi M, Song C, Ikei H, Ohira T, Miyazaki Y (2014) Effect of olfactory stimulation by fresh rose flowers on autonomic nervous activity. J Altern Complement Med 20:727-731

18. Ikei H, Komatsu M, Song C, Himoro E, Miyazaki Y (2012) The physiological and psychological relaxing effects of viewing rose flowers in office workers. J Physiol Anthropol 33:6

19. Kobayashi H, Song C, Ikei H, Kagawa T, Miyazaki Y (2015) Analysis of individual variations in autonomic responses to urban and forest environments. Evid Based Complement Altern Med 2015:671094

20. Tsunetsugu Y, Miyazaki Y, Sato H (2002) The visual effects of wooden interiors in actual-size living rooms on the autonomic nervous activities. J Physiol Anthrop Appl Hum Sci 21:297-300

21. Tsunetsugu Y, Miyazaki Y, Sato H (2007) Physiological effects in humans induced by the visual stimulation of room interiors with different wood quantities. J Wood Sci 53:11-16

22. Sakuragawa S, Miyazaki Y, Kaneko T, Makita T (2005) Influence of wood wall panels on physiological and psychological responses. J Wood Sci 51:136-140

23. Sakuragawa S, Kaneko T, Miyazaki Y (2008) Effects of contact with wood on blood pressure and subjective evaluation. J Wood Sci 54:107-113 